\section{Asthmatikerin in der Menopause: Wann Knochendichte messen?}

\section{Auf dem diesjährigen AAAAI-Kongreß wurde eine kleine Studie vorgestellt, die sich mit dem Einfluß von inhalativen Kortikoiden auf den Knochenstoffwechsel bei menopausalen Frauen befaßte.}

Patienten, die z.B. wegen einer chronischen Polyarthritis langfristig mit systemischen Kortikoiden behandelt werden, benötigen fast ausnahmslos eine Osteoporoseprophylaxe. Doch wie sieht es bei Asthmatikerinnen aus, die über längere Zeit inhalative Steroide applizieren? Auch hier gibt es Hinweise, daß sich die Knochendichte bei einigen dieser Patientinnen speziell in und nach den Wechseljahren auffällig vermindern kann.

Eine US-amerikanische Arbeitsgruppe (B. M. Reddy et al.) wollte Näheres über die quantitativen Zusammenhänge von eingenommener Kortikoiddosis und Knochendichteverlust erfahren. Die Ergebnisse wurden anläßlich des diesjährigen Treffens der
American Academy of Allergy, Asthma and Immunology in Orlando/Florida präsentiert.

Rekrutiert wurden für die Untersuchung 30 Asthmapatientinnen, die lange Zeit inhalative Steroide eingenommen hatten; 22 von ihnen $(73,4 \%)$ befanden sich bereits in der Postmenopause. Je nach Kortikoiddosis ordnete man die Patientinnen einer Niedrig-, Mittel- und Hochdosisgruppe (entsprechend den Richtlinien des National Institut of Health 1997) zu und unterzog sie einer Knochendichtemessung.

Alle 17 Frauen, die in dieser Messung eine statistisch signifikant verringerte Knochendichte aufwiesen, waren postmenopausal. Dabei zeigte sich ein

\section{Kortikoide bei Kindern: Kein Einfluß auf den Knochenmetabolismus}

Eine weitere Studie gibt Entwarnung: Asthmakinder unter einer Kortikoidtherapie müssen keine Beeinträchtigung des Knochenstoffwechsels befürchten. Zu diesem Ergebnis kam J. M. DeMasi, New York/USA, in einer Untersuchung an einem allerdings recht kleinen Patientenkollektiv, die auf dem diesjährigen AAAAI-Kongreß in Orlando vorgestellt wurde.

Die Studie umfaßte 31 Kinder im Alter zwischen 1 und 6 Jahren, von denen 9 intermittierendes leichtes, 6 persistierend leichtes, 4 mittelschweres und 3 schweres Asthma hatten. Ihre Serumkortisol- und Osteolaktinwerte wurden denen einer Gruppe von 9 nicht-asthmatischen Kindern gegenübergestellt. Es stellte sich heraus, daß unabhängig von Dosis, Applikationsweg und Gesamtdauer der Kortikoidtherapie keines der Asthmakinder eine Beeinträchtigung des Knochenstoffwechsels im Vergleich zu den gesunden Kindern zeigte.

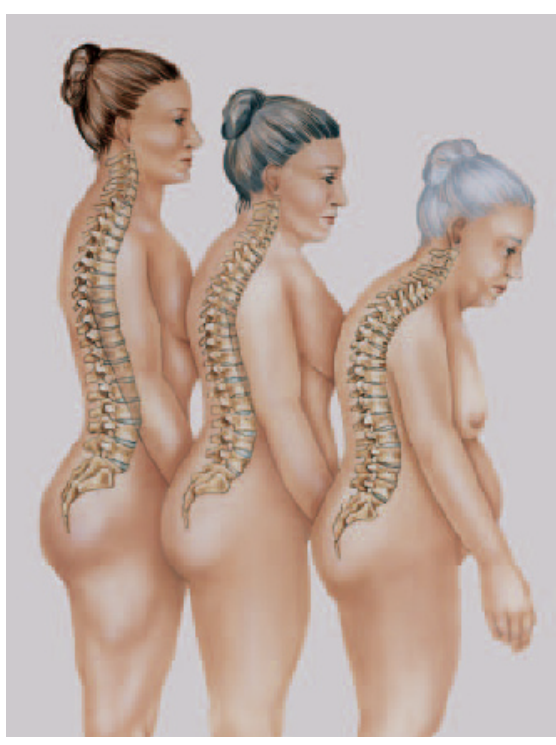

Die Entwicklung einer Osteoporose in der Postmenopause ist von verschiedenen Risikofaktoren abhängig, so z.B. von mangelnder Bewegung, von der Ernährung sowie dem Nikotin- und Alkoholkonsum. Auch systemische Kortikoide können, lange und hochdosiert gegeben, die Knochendichte vermindern. Inhalative Kortikoide sind dagegen sehr viel besser verträglich.

eindeutiger Zusammenhang zwischen der Höhe der eingenommenen Kortikoide und dem zu erwartenden Substanzverlust $(\mathrm{p}<0,034)$ der Knochen, gemessen in Wirbelsäule und Hüfte: Davon betroffen waren 2 von 7 Frauen in der Niedrigdosisgruppe, 9 von 16 in der Mitteldosisgruppe und 6 von 7 Frauen in der Hochdosisgruppe.

Fazit der Autoren: Asthmatikerinnen, die über längere Zeit hochdosiert inhalative Kortikoide eingenommen haben, sollten spätestens mit Einsetzen der Menopause einer Osteodensiometrie unterzogen werden, evtl. verbunden mit einer zusätzlichen Röntgenkontrolle. Auch eine regelmäßige Überprüfung der Serum-Kalziumwerte ist empfehlenswert. Dies macht umso mehr Sinn, als daß es heute mit Hormonsubstitution und der ausreichenden Zufuhr von Vitamin D und Kalzium - am besten kombiniert mit dem Rat, sich sportlich zu betätigen - möglich ist, das Ausbrechen von Osteoporosesymptomen zu verhindern. $b k$

American Academy of Allergy, Asthma and Immunology, 55th Annual Meeting, Orlando/Florida/USA, 1999. Reddy BM, Vilar MB, Silverman BA, et al. Abstract Nr. 884 in J Allergy Clin Immunol 1999; 103 (1, Part 2): S 229. 